\title{
The mechanics property analysis of the electronic bicycle's driving wheel on detecting set
}

\author{
Chao $\mathrm{Xu}^{1, \mathrm{a}}$, Hongbin $\mathrm{Yu}^{2, \mathrm{~b}}$ \\ ${ }^{1}$ School of Mechanical Engineering, Tianjin Polytechnic University, Tianjin 300387, China; \\ ${ }^{2}$ School of Mechanical Engineering, Tianjin Polytechnic University, Tianjin 300387, China. \\ achaoc_xu@163.com, bhongbinyu@aliyun.com
} Keywords: Electric bicycle; Detection platform; Road resistance; Driving force; Mechanics
analysis.

\begin{abstract}
Electric vehicle traffic accident frequency, in order to solve practical problems, so we design and develop electric bicycle testing platform. Around the power, speed, axle load, such as technical indicators, according to the national standard of electric bicycles, electric bicycles in all kinds of parameter evaluation. The mathematical model of electric bicycle driving resistance were analyzed. Combining with the kinetic energy theorem, the kinetic energy of the mathematical model of electric bicycles in a horizontal road. On the basis of kinetic energy is equal to establish the mathematical model of simulation of inertia. In testing platform to analyze dynamic characteristic of the electric bicycle drive wheels.
\end{abstract}

\section{Introduction}

As the national energy gap and environmental pressure increasing, further highlight of urban road congestion, because the electric car has no exhaust gas pollution, no noise, light and beautiful wait for a characteristic, get the favour of many consumers ${ }^{[1]}$.At the same time as the green environmental protection product is supported by national policy.The vigorous development of the electric bicycle industry at the same time, also caused a series of problems, the most serious problem is the quality of the products and electric performance is uneven.

Along with our country electric bicycle quantity increased at the same time, the traffic accidents caused by electric bicycle has increased. Because in the process of traffic accident, car accident is the important basis of motor vehicle is divided into accident liability, therefore, the accident vehicle recognition of electric bicycles, namely the cognizance of the car accident of motor vehicle or a non-motor vehicle is of vital importance.

This paper developed a simple and practical electric bicycle vehicle comprehensive performance test bed, this test board can realize the main electric properties of the electric bicycle automatic and intelligent test index and other parameters. In order to improve the inspection accuracy, make the test platform to simulate the electric bicycle drive wheels moving, the dynamic characteristics of electric bicycle on the road and the dynamic characteristic analysis on the test platform, to get dynamic characteristic of the driving wheel on the test platform.

\section{Detection platform system design principle}

Electric bicycle detection system mainly deal with is closely related to the product performance and safety specifications for testing and quantitative evaluation. Test object of this test bench are mainly car accident, according to the national standard to found excessive tested vehicle. The national standard is "over $40 \mathrm{~kg}, 20 \mathrm{~km} / \mathrm{h}$ electric bikes, called portable electric motorcycle or electric motorcycle, delimit motor vehicles". Therefore, detection of the main indicators are axle load, speed and power.

Scheme design is based on the car accident to begin, in perfect condition for different testing parts used for different shape. According to different vehicle condition to select the test module, the test system by the control driver module, fast charging module and signal test unit module. 
System in the actual test work, the main and auxiliary testing unit selection is as follows:

Table 1 The unit of work table

\begin{tabular}{lccc}
\hline \multicolumn{1}{c}{ work unit } & charger module & $\begin{array}{c}\text { DC power supply } \\
\text { module }\end{array}$ & $\begin{array}{c}\text { control driver } \\
\text { module }\end{array}$ \\
\hline $\begin{array}{l}\text { Battery out of service } \\
\text { Low battery }\end{array}$ & $\checkmark$ & $\checkmark$ & \\
$\begin{array}{l}\text { Damage of motor drives } \\
\text { Above all (Dc motor is normal) }\end{array}$ & $\sqrt{ }$ & $\sqrt{ }$ & $\sqrt{ }$ \\
\hline
\end{tabular}

\section{Test platform of the mechanical structure design and the way to work}

According to the requirement of the system detection, electric bicycle testing platform is mainly composed of friction test bed body, roller, direct current generator, photoelectric encoder, automatic clamping device, field measurement and control module based on ATMEGA16A and upper machine and its peripherals, etc.

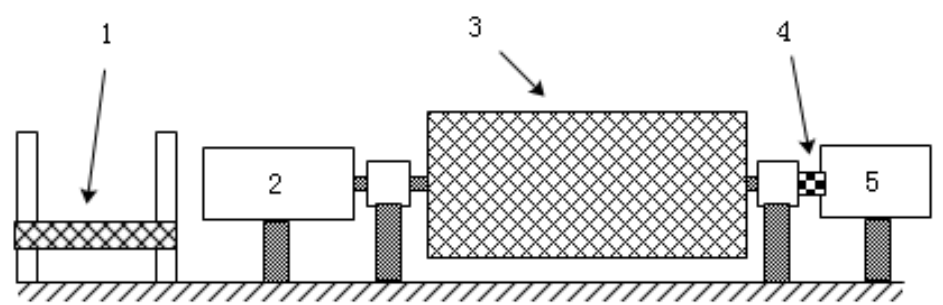

1. weigh pad, put pressure sensors on the gantry; 2. electric generator; 3.rollers set; 4.coupling; 5. encoder

Fig. 1 The mechanical structure diagram

Platform is an intelligent test combined with mechanical and electrical integration of computer aided testing system, its function is to test the parameters for dynamic data acquisition, real-time analysis, data storage, display results ${ }^{[2]}$. Detection system test platform is electric bicycle key performance indicators of important test equipment, its main function is to help maintain the speed of the electric bicycle, at the same time for electric bicycle on the road when driving resistance and electric bicycle to simulate the mechanical inertia.

Control system software design and development of the electric bicycle detection system has a vital role, according to the national standard, DB33/ 572-2005 《Electric bicycle safety technical requirements》, CCGF 213.5-20《Electric bicycle spot check specification》 and GB 17761 《Electric bicycle general technical conditions $\rangle$, for the requirement of control system software design and development, in order to achieve the overall design of control system software ${ }^{[3]}$.

Software is closely related to the hardware, software on the basis of the hardware structure of the complete realization of system functions by the software, to achieve better communication effect, system USES the fieldbus technology ${ }^{[4]}$. This test platform of modular design, software design make full use of MCU software structure is clear, the system main program can be divided into several functional modules: data collection module, data processing module, wireless communication module and display module results. 


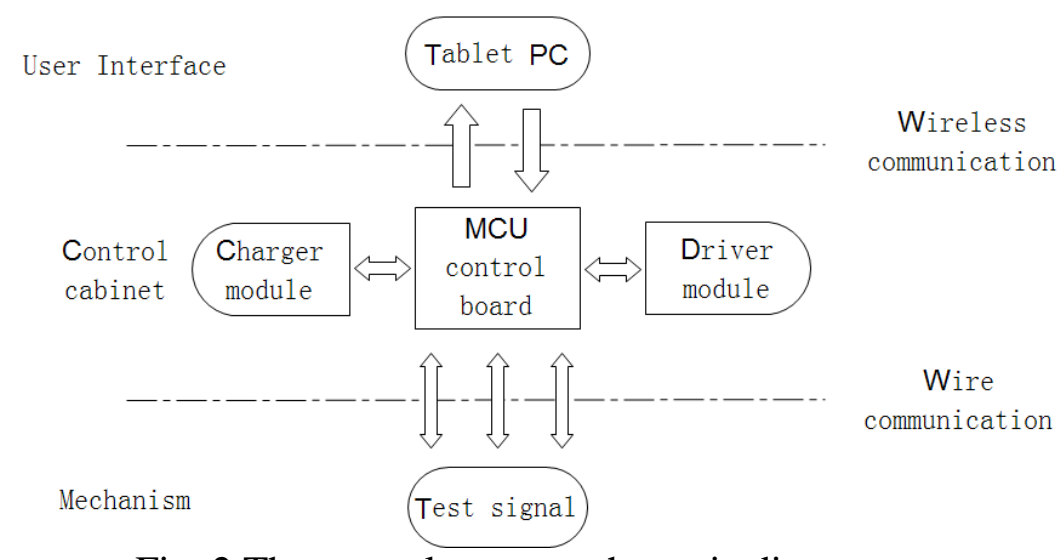

Fig. 2 The control system schematic diagram

\section{The movement of the electric bicycle mechanics analysis}

\subsection{Electric bicycle mechanics analysis}

Due to the test bed are at work, electric bicycle and test board remained relatively static, can take the wind resistance $F_{w}=0$. Electric bicycle is placed on the test bench, the entire weight of the electric bicycle $(\mathrm{M}+\mathrm{m}) \mathrm{g}$ has no angle with the ground, so just considering the friction between the wheel and roller, the friction force and the driving wheel friction with the ground. Electric bicycle driving resistance and gravity analysis diagram is as follows:

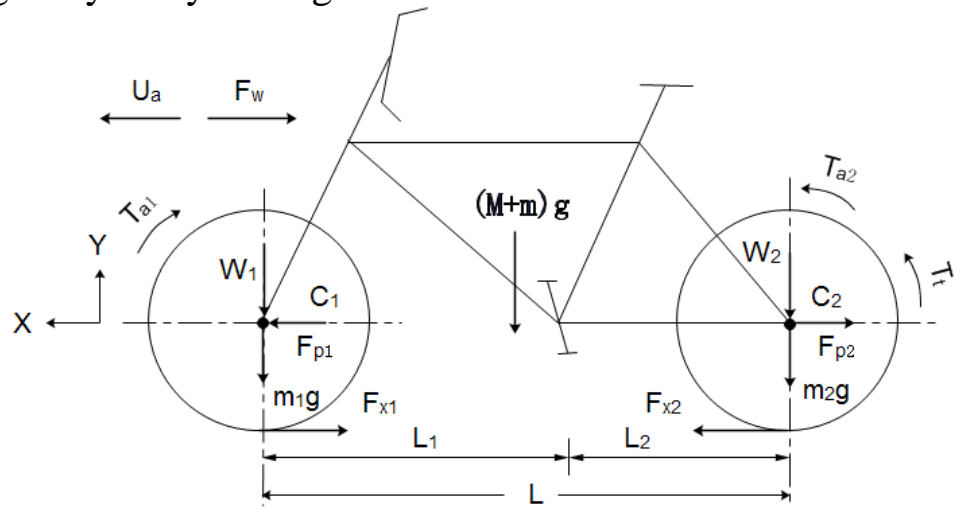

Fig. 3 Electric bicycle driving resistance and gravity analysis diagram

According to the principle of mechanics related, there are relative sliding between the wheel and the roller is not case, if the resistance moment of friction roller is equal to the road to exercise bike by resistance moment, the two are equivalent. Therefore, the principle of roller design is to ensure that the rotational inertia of the drum rotates is equal to the moment of inertia of plane electric bicycle, can get the rotational inertia of the rollers $I=(m+M) R^{2[5]}$.

4.2 The kinetic energy of electric bicycles in the actual road sports ${ }^{[6]}$

Set the quality of the electric bicycle is $\mathrm{M}$, on the road is the speed of $\mathrm{V}$, is the kinetic energy of the electric bicycle riding:

$$
W=\frac{1}{2} M V^{2}+\frac{1}{2}\left(I_{w 1}+I_{w 2}\right) \omega_{w}^{2}
$$

Where : $W$ — The kinetic energy of electric bicycles, unit $\mathrm{J}$;

$M$ - The quality of the electric bicycle, the unit kg;

$\mathrm{V}$ — The speed of electric bicycle, the unit of $\mathrm{m} / \mathrm{s}$;

$\omega-$ The motion of the electric bicycle wheel angular velocity, the unit rad/s;

$I_{w 1}$ - Transmission, motor and drive rotation to the equivalent inertia of the driving wheel unit $\mathrm{kg} \cdot \mathrm{m}^{2}$; 
$I_{w 2}$ The rotational inertia of the driven pulley, the unit $\mathrm{kg} \cdot \mathrm{m}^{2}$

Set of electric bicycle wheel radius, speed, formula (4-1) into:

$$
W=\frac{1}{2} M V^{2}+\frac{1}{2}\left(I_{w 1}+I_{w 2}\right) \frac{V^{2}}{R^{2}}
$$

\subsection{The kinetic energy of electric bicycle on the test platform motion}

Set up the quality of the electric bicycle is $\mathrm{M}$, speed on the test platform is $\mathrm{V}$, motion is kinetic energy:

$$
W^{\prime}=\frac{1}{2} I_{w 1} \omega_{w}{ }^{2}+\frac{1}{2} I_{B M} \omega_{r}^{2}
$$

Where: $W^{\prime}$ — The kinetic energy of electric bicycle, J;

$\omega_{r}$ — The angular velocity of roller, the unit rad/s;

$\omega_{w}$ — The motion of the electric bicycle wheel angular velocity, the unit rad/s;

$I_{B M}$-Detection system equivalent to the moment of inertia of top roller, the unit $\mathrm{kg} \cdot \mathrm{m}^{2}$.

Set $\omega_{w}=V / R ; \omega_{r}=V / r$ (4-3) into that formula:

$$
W^{\prime}=\frac{1}{2} I_{w 1} \frac{V^{2}}{R^{2}}+\frac{1}{2} I_{B M} \frac{V^{2}}{r^{2}}
$$

By the kinetic energy is equal to, $W=W^{\prime}$

$$
I_{B M}=M r^{2}+\frac{r^{2}}{R^{2}} I_{w 2}
$$

4.4 Electric bicycle in the practical road of the driving wheel dynamic movement

By the theory of electric bicycles, when quality for $\mathrm{M}$ electric bicycle on the road in a speed $\mathrm{V}$ movement, dynamic equations of motion for:

$$
\delta M \frac{d V}{d t}=F_{t}-M g f-\frac{C_{D} A V^{2}}{21.15}
$$

Where: $F_{t}$ Electric bicycle when driving force, the unit N;

g-Gravity acceleration, $g=9.8 \mathrm{~m} / \mathrm{s}^{2}$;

$\mathrm{f}$ - Electric bicycle at rolling resistance coefficient;

$\mathrm{C}_{\mathrm{D}}$-Coefficient of air resistance;

$A$-Electric bicycle windward area, the unit $\mathrm{m}^{2}$;

$\delta$ - The rotation of the electric bicycle quality conversion factor;

$d V / d t$ - The motion of the electric bicycle acceleration, the unit $\mathrm{m} / \mathrm{s}^{2}$.

When the quality of $\mathrm{M}$ constant speed in a electric bicycle on the road in a speed $\mathrm{V}$, the acceleration is zero, namely the $\mathrm{dV} / \mathrm{dt}=0$, the driving force for:

$$
F_{t}=M g f+\frac{C_{D} A V^{2}}{21.15}
$$

\subsection{Electric bicycle on test platform testing dynamic characteristic of the driving wheel}

To test the electric bicycle on the test platform, assuming that electric bike driving wheel and test platform of the surface of the roller no skid phenomenon, the motion equations of the electric bicycle:

$$
\left(\frac{r}{R} I_{w 1}+\frac{R}{r} I_{B M}\right) \frac{d \omega_{w}}{d t}=r F_{t}-T_{e}-T_{B}-\frac{f_{r}(R+r)}{\cos \alpha} Z_{1}
$$

Where: $r$-Roller radius, unit $m$;

$\mathrm{Z}_{1}$ _Electric bike driving wheel vertical load, unit $\mathrm{N}$;

$d \omega / d t$ - The driving wheel angular acceleration, unit rad/s; 
$T_{e}$ — Test platform of dynamometer drum load torque, unit $\mathrm{N} \cdot \mathrm{M}$;

$\mathrm{T}_{B}$ — Total internal resistance torque test platform, unit $\mathrm{N} \bullet \mathrm{M}$;

$f_{r}$-Wheel material, pressure, the coefficient of load and speed of electric bicycle and so on.

In the constant speed in a electric bicycle on the test platform, angular acceleration is zero, be $d \omega / d t=0$, so the driving force for:

$$
F_{t}=\frac{1}{r}\left(T_{e}+\frac{f_{r}(R+r)}{\cos \alpha} Z_{1}+T_{B}\right)
$$

Under the the speed, it is assumed that because the output torque of the motor changes caused by the electric bicycle drive changes $\Delta F_{t}$, the angular acceleration for electric bikes is:

$$
\frac{d \omega_{w}}{d t}=\frac{r \Delta F_{t}}{\frac{r}{R} I_{w 1}+\frac{R}{r} I_{B M}}
$$

\subsection{On the basis of the driving wheel dynamic characteristics mathematical model to simulate the inertia of the same}

Suppose you want to make the same driver $\Delta F_{t}$, electric bicycle driving wheel on the test platform and practical dynamic characteristics of the road are the same, $d \omega / d t=d \omega_{w} / d t$, before the test platform into drum of IBM should meet the condition that the general simulation of inertia:

$$
I_{B M}=\delta M r^{2}-\frac{r^{2}}{R^{2}} I_{w 1}
$$

By comparing the formula (4-5) and formula (4-11), the calculation results are equal.

In the formula (4-8), it was assumed that when the electric bicycle drive change $\Delta F_{t}$, at the same time change the load torque test platform, by adding a variable $\Delta T_{e}$, the electric bike driving wheel angular acceleration for at this time:

$$
\frac{d \omega_{w}}{d t}=\frac{r \Delta F_{t}-\Delta T_{e}}{\frac{r}{R} I_{w 1}+\frac{R}{r} I_{B M}}
$$

Therefore, in order to make the electric bicycle on the test platform has the same dynamic movement and the actual road, torque increment $\Delta T_{e}$ shall meet the following conditions:

$$
\frac{r \Delta F_{t}-\Delta T_{e}}{\frac{r}{R} I_{w 1}+\frac{R}{r} I_{B M}}=\frac{\Delta F_{t}}{\delta M \cdot R}
$$

$\delta=1+\frac{I_{w 1}+I_{w 2}}{M R^{2}}$ into formula (4-13):

$$
\Delta T_{e}=\frac{M \cdot R \cdot r+\frac{r}{R} I_{w 2}-\frac{R}{r} I_{B M}}{\delta M \cdot R} \Delta F_{t}
$$

On the basis of the quality of the inertia of the driven wheel electric bicycle is much lower than electric bicycle translation quality, $I_{w 2} \ll M R^{2}$, so the formula (4-14) is simplified to:

$$
\Delta T_{e}=\frac{M r^{2}-I_{B M}}{\delta M r} \Delta F_{t}
$$

Is derived based on the above, to make the electric bicycle on the test platform motion dynamic characteristic of the driving wheel is the same as the actual road, just make sure the test platform load torque increment meet formula (4-14) or formula (4-15) can meet the conditions. 


\subsection{Simulation analysis of friction under road}

To simulate the effect of electric bicycles in the actual surface road, make lathe processing complete roller surface friction and the actual asphalt, then place the electric bicycle in test run on stage. Test platform with electric bicycle wheel force transfer and friction coefficient on the surface of the test bed roller is an important process parameters.

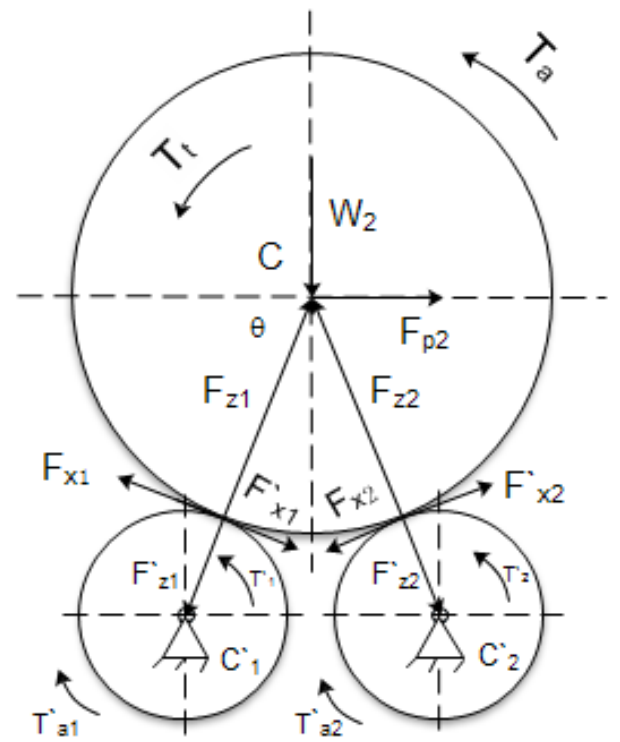

Fig. 4 Between the roller and wheel force analysis diagram

As can be seen from the above, the reaction of 1 for wheel cylinder $F_{z 1}$ and level into $\theta$ Angle, that is to say $F_{z 1}$ in vertical direction and $F_{z 2}$ resultant force is equal to the $W_{2}$, namely $W_{2}=$

$\left(\mathrm{F}_{\mathrm{z} 1}+\mathrm{F}_{\mathrm{z} 2}\right) \sin \theta$. Wheels and the friction between the two rollers are equal, $\mathrm{F}_{\mathrm{x} 1}$ and in the horizontal component of $F_{x 2}$ is equal to the sum of $F_{p 2}, F_{p 2}=\left(F_{x 1}+F_{x 2}\right) \sin \theta$. To make the operation of the electric bicycle on the inspection car, resistance $F_{p 2}$ received the same as the real road surface friction coefficient, to machining the cylinder surface, make it meet the requirements of the friction $^{[7]}$.

\section{Summary}

Based on the above electric bicycle riding under the condition of driving mechanics analysis, the dynamic characteristic of the electric bicycle drive wheels.For electric bicycle on the testing platform, simulate the dynamic behavior of the driving wheel provides the parameters. Electric testing platform of various technical indicators have reached the design requirement, can accurate detection for electric car accident. This testing platform development, will provide convenience for electric car accident detection at the same time, also will be rapid development according to the national standard for electric bicycle, play a positive role.

\section{References}

[1] Pan Jin. Based on research of electric bicycle brushless motor control system and design [D]. Central south university, 2012.

[2] Chen Qingtao. .net and distributed (network) database integration under the technical support of research and development of WEB GIS system [D]. Chengdu university of technology, 2008.

[3] Jin Yun. GB17761 general technical conditions "electric bicycle", recently released draft [J]. Electric bicycle, 2013, 12:1.

[4] Wang Zheng. Fieldbus communication technology [D]. The research and implementation of daqing petroleum institute, 2004. 
[5] Qin Yao. Commonly used even the moment of inertia of rigid body in this discussion [J]. Journal of college physics, 2002, 21 (2) : 39-41.

[6] Ren You, HongGuo Xu, Li Xiansheng. Electric bicycle chassis dynamometer inertia system development research [J]. Highway traffic science and technology, 2002, 12 (3) : 141-143.

[7] Ma Bin, HongGuo Xu, HongFei Liu. The road tire and rubber fractal features of the influence of sliding friction factor [J]. Journal of jilin university (engineering science), 2013, 11:317-322. 